\title{
Inundation risk assessment of underground spaces in the downtown of Fukuoka City, Japan
}

\author{
H. Hashimoto ${ }^{1} \&$ K. Park $^{2}$ \\ ${ }^{1}$ Department of Civil Engineering, Kyushu University, Japan \\ ${ }^{2}$ Ecological River Environmental Technique Institute, South Korea
}

\begin{abstract}
Two flood events, which were due to short-time heavy rainstorms, hit the downtown of Fukuoka City in Japan in 1999 and 2003. The Mikasa River in this city overflowed its banks, and then the overflowing water moved down the roads to the railroad station, called 'Hakata-eki'. This area is a dense downtown with many office buildings and underground spaces utilized for restaurants, parking garages, shopping malls and a subway station. The flooding water inundated the basements of many buildings and the other underground spaces. The purpose of the present study is to develop an inundation risk assessment method for underground spaces. Firstly, two types of underground spaces near the 'Hakataeki' railroad station can be distinguished; one is a small-scale underground space utilized for restaurants and parking garages, and the other is a large-scale underground space for a subway station and shopping malls. Secondly, the floodwater behaviour within the two types of underground spaces is simulated. Finally, on the basis of the simulation, a method for risk assessment of inundation of underground spaces due to a flood event is proposed.
\end{abstract}

Keywords: urban flood, underground space, flood risk management.

\section{Introduction}

A heavy rainstorm hit Fukuoka City in Japan on June 29, 1999. Rainfall began at 4:00 p.m. on June 28 and ended at 11:00 a.m. on June 29. The main rainfall lasted from 6 to 10 a.m. on June 29. The accumulated rainfall was $159.5 \mathrm{~mm}$ from 4:00 p.m. on June 28 to 11:00 a.m. on June 29 . The largest hourly rainfall 
was $77 \mathrm{~mm}$ /hour from 8 to 9 a.m. on June 29. The Mikasa River and the tributary called the 'Sanno channel' overflowed. The river surface level began to increase at around 6:00 a.m., and the overflow began at around 9:00 a.m. on June 29. The overflowing water moved down the roads to the railroad station, called 'Hakataeki'. This area is a dense downtown with many office buildings and underground spaces utilized for parking garages, restaurants, shopping malls and a subway station. The flooding water inundated the basements of many buildings and the other underground spaces, such as the subway station and the shopping malls. This resulted in a drowned person, who was working at that time for a restaurant in the basement of a building. This revealed a hazard of inundation of underground spaces to citizens during heavy rain.

Furthermore, a short-time heavy rainstorm hit Dazaifu City in a suburb of Fukuoka City on July 19, 2003. Dazaifu City is located in the upstream region of the Mikasa River basin. The rainfall lasted from 1:00 to 8:00 a.m. on July 19 . The accumulated rainfall was $315 \mathrm{~mm}$ and the largest hourly rainfall was 99 $\mathrm{mm} /$ hour from 4:00 to 5:00 a.m. The Mikasa River and the tributary called 'Sanno channel' overflowed near 'Hakata-eki' station. The river surface level began to increase around 2:00 a.m., and the overflow began around 4:00 a.m. 'Hakata-eki' railroad station and the underground spaces around the station were inundated. This inundation is the second one since the 1999 flood event. Inundation risk assessment of underground spaces in the downtown of Fukuoka City has become important.

The purpose of the present study is to investigate the use and characteristics of the underground spaces and to develop an inundation risk assessment method of underground spaces.

\section{Inundation situation of underground spaces during the 1999 flood event}

Figure 1 shows the situation of the 1999 flood event and the positions of entrances of the underground spaces utilized for parking garages, restaurants, shopping malls and a subway station. The number of inundated underground spaces was 23. The outline of inundation of the underground spaces is as follows:

(1) A building near Position A had a steel barrier installed at the entrance of the underground parking garage to prevent flooding water from entering the garage. Although it was $40 \mathrm{~cm}$ high, flooding water overflowed the barrier and inundated the garage. The amount of inundation water was $1,995 \mathrm{~m}^{3}$.

(2) The subway station is in the underground of the 'Hakata-eki' railroad station. The immediate vicinity of Position $\mathrm{C}$ (the east side of 'Hakata-eki' railroad station) has five entrances to the subway station; they are called 'Entrance 12', 'Entrance 13', 'Entrance 14', 'Entrance 15' and 'Entrance 17'. Flooding water began to enter 'Entrance 17' at 10:42 a.m., and then the other entrances at 11:00 a.m. As a result, water volume of about $2,000 \mathrm{~m}^{3}$ flowed into the subway station. 


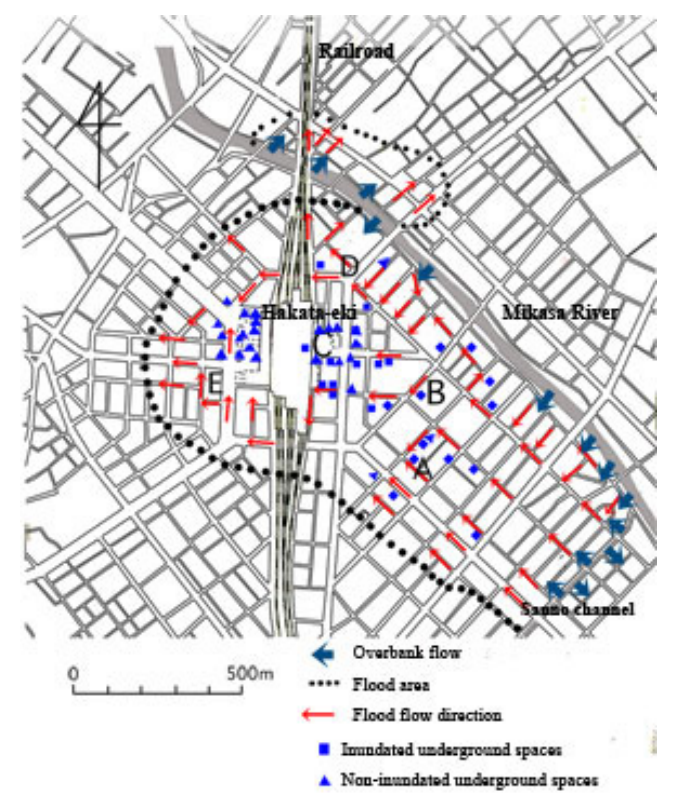

Figure 1: Situation of the 1999 flood event and the location of the underground spaces in the flood area (after the work of Hashimoto et al. [1]).

\section{Investigation into underground spaces after the 1999 flood event}

We investigated the use, entrances, and areas of underground spaces from June 25, 2002 to February 8, 2003. Their inundation depth and volume due to the 1999 flood event were also examined. Figure 2 shows the use of the inundated underground spaces. There were mainly 15 parking garages and eight restaurants in the flood area. Figures 3-5 show the characteristics of the entrances of inundated underground spaces. The entrances of underground spaces have two types of floor: one is step and the other is slope (figure 3). The floor of 16 entrances is step and that of 14 entrances is slope. The former is for restaurants and the latter for parking garages. Figure 4 shows the scale of entrances of the underground spaces. We find that there are many underground spaces with their narrow entrances such that $2 \mathrm{~m}>\mathrm{W}>1 \mathrm{~m}$. Here $\mathrm{W}$ indicates the width of the entrances. The use of these underground spaces is restaurants. The use of the underground spaces with their wider entrances such that $\mathrm{W}>4 \mathrm{~m}$ is parking garages. Figure 5 shows the slope angle of the entrance floors of the underground spaces. The floor slope of the parking garages at the entrances is from $5^{\circ}$ to $15^{\circ}$. That of the restaurants at the entrances is from $25^{\circ}$ to $40^{\circ}$. The restaurants have narrow entrances and steep stairways. We can see that it is difficult for us to escape from inundated restaurants while the flooding water 


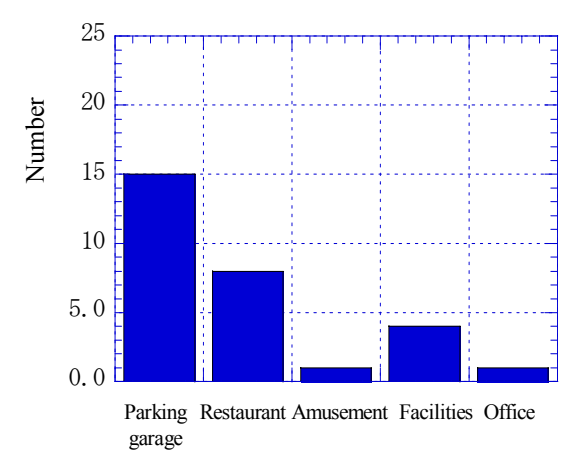

Figure 2: Use of underground spaces inundated during the flood event in 1999.

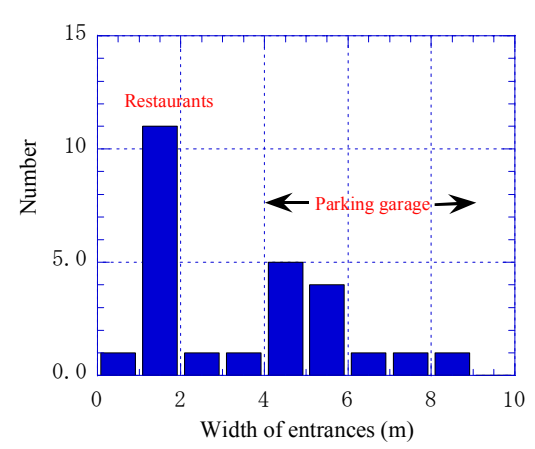

Figure 4: Scale of entrances of the inundated underground spaces during the 1999 flood event.

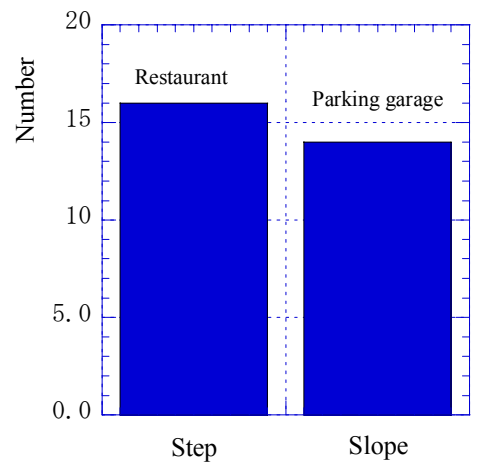

Figure 3: Characteristics of the floor at entrances of the inundated underground spaces during the 1999 flood event.

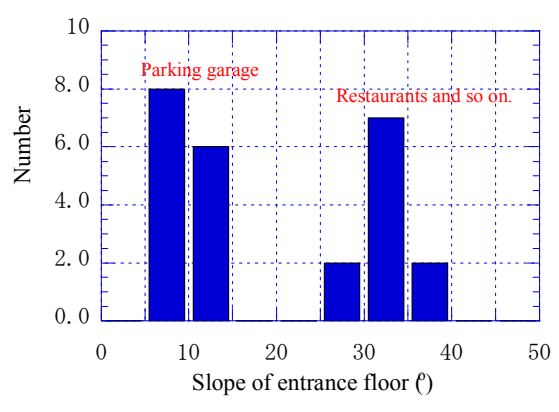

Figure 5: Slope angle of the entrance floors of the inundated underground spaces during the 1999 flood event.

enters the restaurants. The underground spaces with entrances wider than the value of $4 \mathrm{~m}$ are parking garages.

Figure 6 shows the floor area of the underground spaces. We find that the floor area of the inundated underground spaces ranges from $90 \mathrm{~m}^{2}$ to $1,710 \mathrm{~m}^{2}$. The underground spaces with a floor area larger than $1,000 \mathrm{~m}^{2}$ are parking garages.

Figure 7 shows the water depth in the inundated underground spaces. The inundation depth varied from $0.2 \mathrm{~m}$ to $5.85 \mathrm{~m}$ and its volume was between 45 and $22,000 \mathrm{~m}^{3}$.

The entrances to the subway station have stepped floors. The width of the entrances ranges from $2.0 \mathrm{~m}$ to $3.25 \mathrm{~m}$. The slope of the entrance floor is about $26^{\circ}$. The inundation water volume of the subway platform amounted to $2,000 \mathrm{~m}^{3}$. 


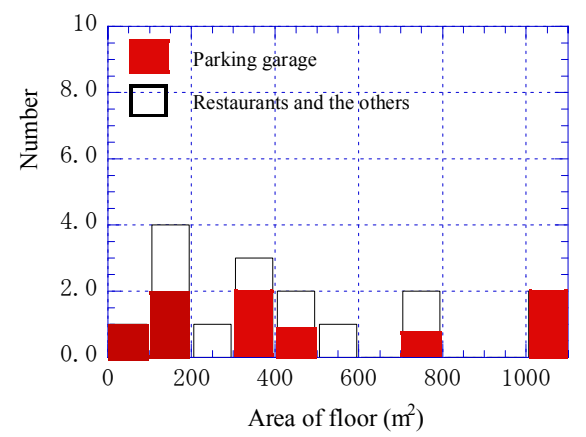

Figure 6: Area of floor of the Figure 7: Water depth of the inundated underground spaces during the 1999 flood event.

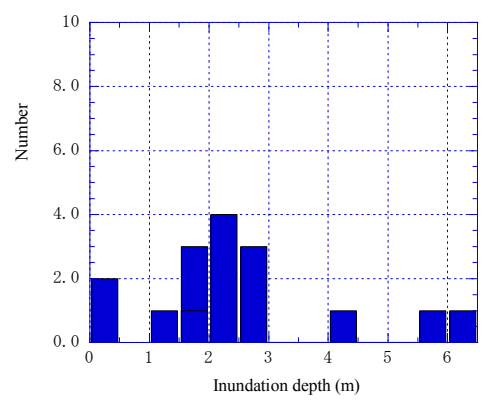
inundated underground spaces during the 1999 flood event.

\section{Investigation into underground spaces after the 2003 flood event}

Firstly, the situation of the flood event in 2003 is described. The heavy rainfall hit Dazaifu City in the upstream region of the Mikasa River basin on July 19, 2003. The Mikasa River and the tributary called the 'Sanno channel' overflowed near to the 'Hakata-eki' railroad station at around 4:00 a.m. on July 19. At that time, four years had passed since the 1999 flood event. Most underground spaces near the Hakata-eki railroad station had adopted countermeasures against flooding. However, the flood event being in the early morning delayed the preparation of the countermeasures. As a result, flooding water from the Mikasa River and the 'Sanno channel' flowed into most of the underground spaces, especially the subway station. The inundation water volume of the subway station amounted to about $10,000 \mathrm{~m}^{3}$. The inundation depth near the ticket checker was about $20 \mathrm{~cm}$ at around 7:00 a.m.

After this flood event, we investigated the inundation situation of the underground spaces from December 2003 to January 2004. The positions of the underground spaces are shown in Figure 8. The number of inundated underground spaces was 38. Figure 9 shows the use of the underground spaces. Most of the underground spaces are utilized as parking garages and restaurants.

Figure 10 compares the inundation volume of the underground spaces during the 2003 flood event with that during the 1999 flood event. We can distinguish three groups of inundated underground spaces as follows:

(1) Three underground spaces on the east side of Hakata-eki railroad station failed to prevent inundation during the 1999 flood event, but succeeded to prevent inundation during the 2003 flood event.

(2) Most of the underground spaces on the east side of the Hakata-eki railroad station failed to prevent inundation during the 1999 and 2003 flood events. 
(3) Most of the underground spaces on the west side of the Hakata-eki station were not inundated during the 1999 flood event. Two of these underground spaces succeeded to prevent inundation during the 2003 flood event, but the others failed to prevent inundation during the 2003 flood event.

Figure 11 shows the number of inundated underground spaces versus their inundation water depth. We can see three groups of inundated underground spaces: the first one is underground spaces with an inundation depth smaller than

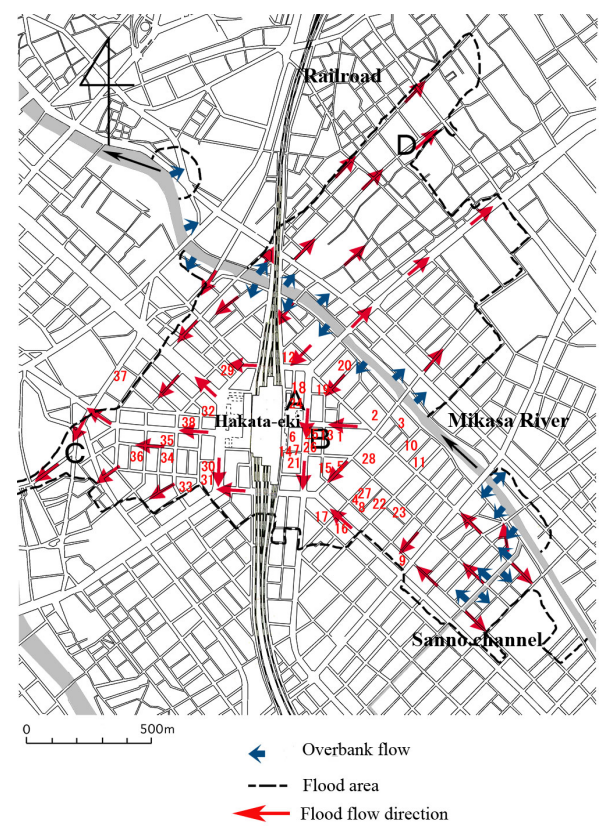

Figure 8: Situation of the 2003 flood event and position of the inundated underground spaces.

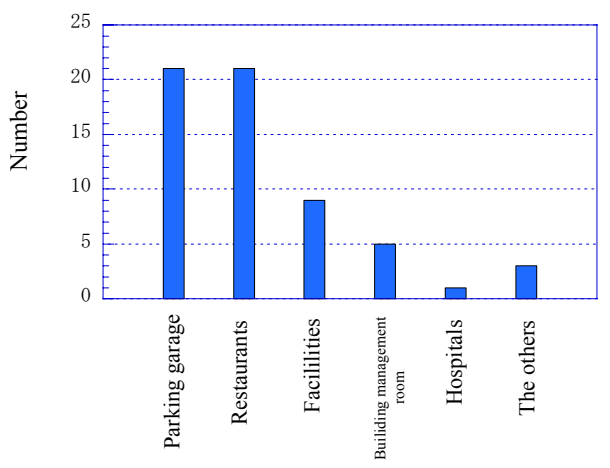

Figure 9: Use of the underground spaces in the flood area during the 2003 flood event. 


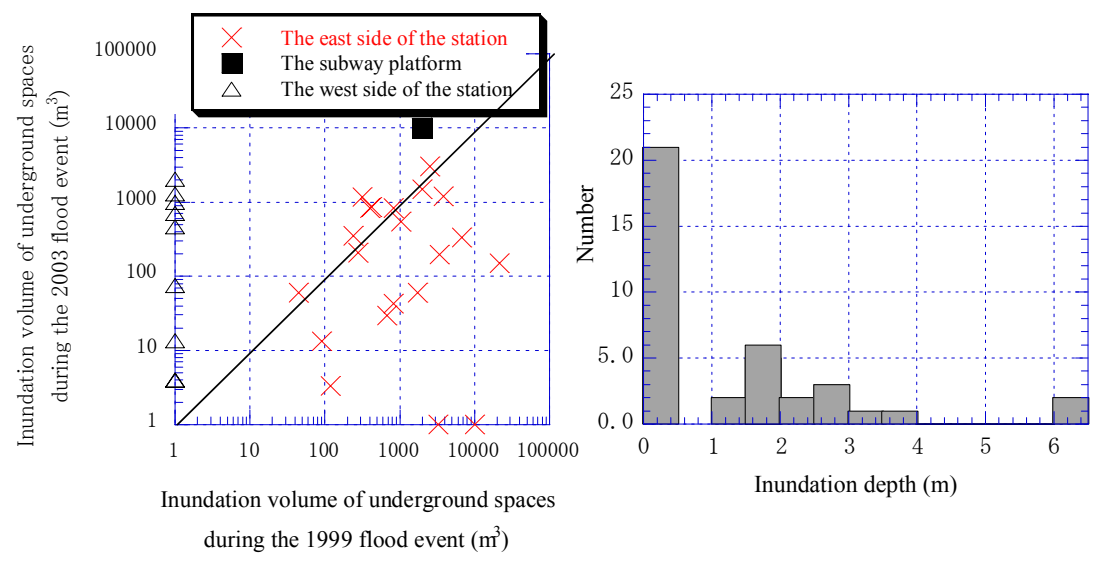

Figure 10: Comparison between Figure 11: Water depth of the inundation volume of underground spaces during the 1999 flood event and inundated underground spaces during the 2003 flood event. that during the 2003 flood event.

$0.5 \mathrm{~m}$, the second one is those with an inundation depth of $1 \sim 4 \mathrm{~m}$ and the third one is those of inundation depths larger than $6 \mathrm{~m}$. This result is similar to that in the 1999 flood event (Figure 7).

\section{Inundation analysis of underground spaces during a flood event}

Underground spaces are divided into two kinds: one is a small-scale underground space utilized for restaurants or parking garages in each building and the other is a large-scale underground space for a subway station or shopping mall. In this section, the index of hazard of inundation is proposed for each kind of underground space.

Inundation volume and time for filling the small-scale underground space with water are computed for time-varying flood flow depth at the entrances on the ground level. The flow velocity and discharge in the large-scale underground space are computed for time varying flood flow depth at the entrances. The flood flow depth at the entrances on the ground level is evaluated by application of the two-dimensional urban flood simulation model to the flood event in 1999 $[2,3]$.

\subsection{Inundation analysis of small-scale underground spaces}

Figure 12 shows time-varying flood flow depth at the entrance of parking garage in the basement of a building at Position A (figure 1). In the 1999 flood event, 
this parking garage had the steel barrier $40 \mathrm{~cm}$ high installed at the entrance. The observation showed that flooding water on the road overflowed the steel barrier at 10:25 on June 29,1999 . On the other hand, the calculation shows that the overflow began at 10:30. We can see the agreement between the observation and the calculation of the initial time of the overflow. Figure 13 shows time variation of inundation water volume of the parking garage. The calculated value of 1742 $\mathrm{m}^{3}$ almost agrees with the observed value of $1995 \mathrm{~m}^{3}$. Considering the area of the parking garage to be $739 \mathrm{~m}^{2}$, the calculated and observed inundation water depth is $2.36 \mathrm{~m}$ and $2.70 \mathrm{~m}$, respectively. It takes 83 minutes for water surface level to increase to height of $2.36 \mathrm{~m}$ in the parking garage. These results are summarized in Table 1.

We can see that inflow water volume, inflow discharge and inflow time for filling the underground space with the floodwater are important parameters for the flood risk assessment of small-scale underground spaces.

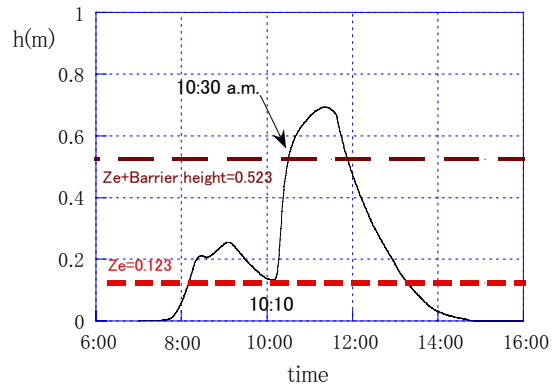

Figure 12: Time-varying flood flow depth at the entrance of the underground parking garage at Position A.

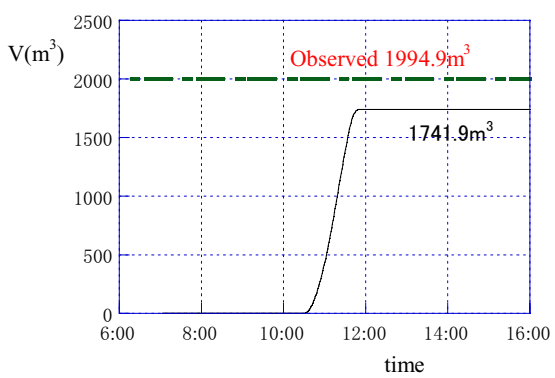

Figure 13: Time variation of inundation water volume of the parking garage.

Table 1: Comparison between the observed and calculated inundation parameters for the inundated parking garage. $\mathrm{H}_{\mathrm{b}}$ : steel barrier height, $\mathrm{t}_{\mathrm{i}}$ : initial time of inundation, $\mathrm{V}$ : inundation volume, $\mathrm{D}$ : inundation depth, $\mathrm{T}_{\mathrm{f}}$ : time taken for the parking garage to be filled with floodwater.

\begin{tabular}{|l|c|c|c|c|c|}
\hline & $\mathrm{H}_{\mathrm{b}}(\mathrm{cm})$ & $\mathrm{t}_{\mathrm{i}}$ & $\mathrm{V}\left(\mathrm{m}^{3}\right)$ & $\mathrm{D}(\mathrm{m})$ & $\mathrm{T}_{\mathrm{f}}$ (minutes) \\
\hline Observations & 40 & $10: 20$ a.m. & 1,995 & 2.70 & \\
\hline Calculations & 40 & $10: 30$ a.m. & 1,742 & 2.36 & 83 \\
\hline
\end{tabular}

\subsection{Inundation analysis of large-scale underground spaces}

We analyze inundation of the subway station called 'Chikatetsu Hakata-eki' during the 1999 flood event. There are several entrances on the ground level to 
the subway station. During the flood event, barriers, such as sandbags and steel barriers, were laid at the entrances to prevent flooding water from entering the subway station. However, we have no information about the height of the barriers. Therefore, we assume the barriers $50 \mathrm{~cm}$ high in this analysis.

Flood flow depth at each entrance of the subway station can be evaluated by application of the two-dimensional urban flood simulation model [2, 3] to the 1999 flood event (figure 14). The flow velocity at each entrance is evaluated by the control section concept. Considering the barriers $50 \mathrm{~cm}$ high, we can estimate overflow discharge at each entrance and integrate the overflow discharge with respect to time. The results are shown in Table 2. We can find that water flooding in the subway station is from Entrances 15 and 17. Entrance 17 is the most dangerous one and Entrance 15 is the second one of all the subway entrances. Investigation into the underground spaces after the 2003 flood event showed that flooding water overflowed the steel barrier $45 \mathrm{~cm}$ high at Entrances 15 and 17.

Therefore, we analyze the behaviour of inflow water from Entrance 17 on the ground level. The subway station called 'Chikatetsu-Hakata-eki' has several parts, such as passage, ticket checker and platform. For the flood flow analysis, the subway station can be divided into three parts. The first one consists of the entrance on the ground level, stairway and passage. The second one, the west part from Position D in the passage, consists of the open space, ticket checker and stairway to the platform (figure 15). Finally, the third one is the platform. Therefore, one-dimensional flood flow analysis is made for the first part and two-dimensional flood flow analysis can be made for the second part (the west one from the Position D). The calculation is made for the period from 10:00 a.m. to 1:00 p.m. on June 29, 1999.

The flood flow along the first part can be treated as one-dimensional unsteady flow. Flood flow discharge $\mathrm{Q}$ and depth $\mathrm{h}$ are unknown variables. Initial condition of the part is dry. Flow discharge and depth as the boundary condition are given at Entrance 17; flow discharge can be evaluated from the critical condition of Froude number $=1.0$ by using the flow depth (figure 14).

Table 2: $\quad$ Inflow water volume from five entrances to the subway station.

\begin{tabular}{|c|c|c|c|c|}
\hline & $\begin{array}{c}\text { Without } \\
\text { barrier }\end{array}$ & $\begin{array}{c}\text { With barrier } \\
40 \mathrm{~cm} \text { deep }\end{array}$ & $\begin{array}{c}\text { With barrier } \\
45 \mathrm{~cm} \text { deep }\end{array}$ & $\begin{array}{c}\text { With barrier } \\
50 \mathrm{~cm} \text { deep }\end{array}$ \\
\hline Entrance 12 & 4,802 & 53 & 0.1 & 0.0 \\
\hline Entrance 13 & 3,905 & 0.0 & 0.0 & 0.0 \\
\hline Entrance 14 & 6,236 & 25 & 0.0 & 0.0 \\
\hline Entrance 15 & 10,470 & 358 & 99 & 1.3 \\
\hline Entrance 17 & 41,300 & 4,510 & 2,996 & 1,813 \\
\hline Total & 66,720 & 4,952 & 3,095 & 1,814 \\
\hline
\end{tabular}


152 Flood Recovery, Innovation and Response II
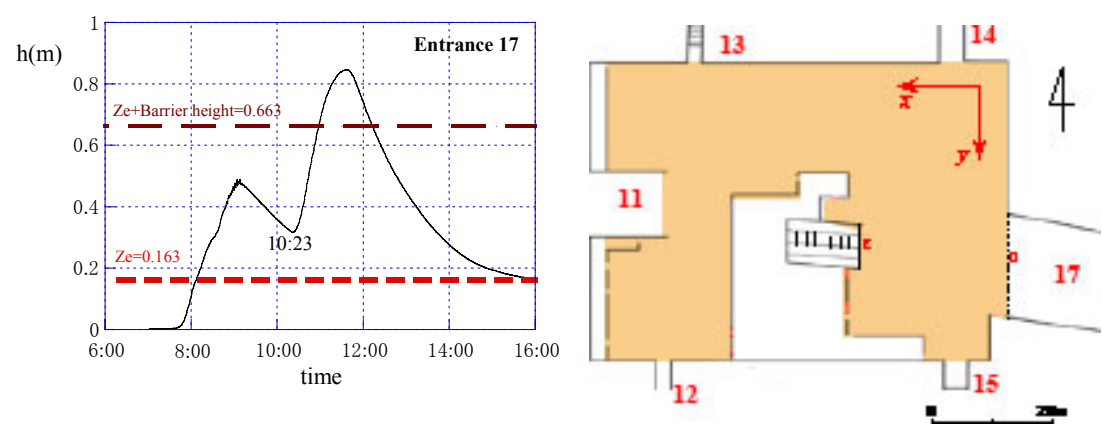

Figure 14: Calculated flood flow depth at Entrance 17 to the subway station. Ze denotes the elevation of the floor of Entrance 17 Figure 15: Open space, ticket checker and stairway to the platform in the subway station. from road.
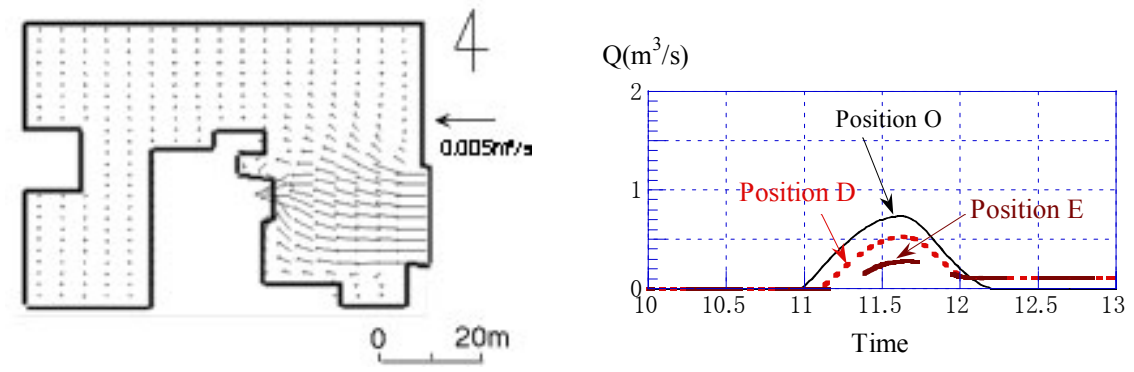

Figure 16: Flow flux vector flooding on the second part of the station at 11:30 a.m. on

Figure 17: Time variation of flood flow discharge at Positions O, D and E. June 29, 1999. Position $\mathrm{O}$ denotes the position of the entrance on the ground level, and Positions D and E denote the ends of the open space in the second part of the subway station (Figure 15).

The flood flow on the second part (the west one from the Position D) can be treated as two-dimensional unsteady flood flow. Initial condition of this part is dry. Flow discharge and depth as the boundary condition are given at Position D from the one-dimensional flood flow calculation. Distance step is $\Delta x=\Delta y=$ $2 \mathrm{~m}$, and time step is $\Delta t=0.1 \mathrm{sec}$. There is a stairway at Position E going down to 
the platform. The flow at this position is assumed in a critical condition of Froude number $=1.0$. Figure 16 shows flow flux vector at 11:30 a.m. on the second part of the station. We can see larger flow flux from Position D to E. The flow depth is found $0.07 \sim 0.09 \mathrm{~m}$. Figure 17 shows time-varying flow discharge at Positions O, D and E. 64\% of flow discharge at Position D flows into the escalator going down to the platform. It is found that the subway platform is most dangerous when flood flow happens around Hakata-eki railroad station.

We can see that flood flow depth and velocity at any position are important parameters for the flood risk assessment of large-scale underground spaces.

\section{Conclusions}

The results obtained in this study are as follows:

(1) Two types of underground spaces can be distinguished; one is small-scale underground space utilized for restaurants and parking garages, and the other is large-scale underground space for a subway station and shopping malls.

(2) Entrance of the underground restaurants has the width of $2 \mathrm{~m}>\mathrm{W}>1 \mathrm{~m}$ and the slope of $40^{\circ}>\mathrm{S}>25^{\circ}$. On the other hand, entrance of the underground parking garages has the width of $\mathrm{W}>4 \mathrm{~m}$ and the slope of $15^{\circ}>\mathrm{S}>5^{\circ}$. The parking garages have wide entrance and mild slope, but the restaurants have narrow entrance and steep stairway.

(3) The entrances to the subway station have the width of $3.25 \mathrm{~m}>\mathrm{W}>2.0 \mathrm{~m}$ and the slope of about $26^{\circ}$.

(4) Inflow water volume, inflow discharge and inflow time for filling the underground space with the flood water are important parameters for the inundation risk assessment of small-scale underground spaces.

(5) Flood flow depth and velocity at any position are important parameters for the inundation risk assessment of large-scale underground spaces.

\section{References}

[1] Hashimoto, H., Matsunaga, K. and Nanri., Y., Flood disaster in Fukuoka City on June 29, 1999, J. JSNDS 20-1, pp. 43-58, 2001 (in Japanese).

[2] Hashimoto, H., Park, K. and Watanabe, M., Overland flood flow around the JR Hakata-eki station from the Mikasa and Sanno-Channel river in Fukuoka city on June 29, 1999, J. JSNDS 21-4, pp. 369-384,2003 (in Japanese).

[3] Hashimoto, H. and Park, K., Two-dimensional urban flood simulation: Fukuoka flood disaster in 1999, First International Conference on Flood Recovery, Innovation and Response, pp.59-67, 2008. 